\title{
Burden of Non-Communicable Diseases in South Asia - A Clinical Review
}

\author{
MD. SALEHUDDIN ${ }^{1}$, KAMRUN NAHAR CHOUDHURY ${ }^{1}$, NEENA ISLAM ${ }^{1}$, MD. ZILLUR RHAMAN ${ }^{2}$, SHANTONU \\ KUMAR GHOSH. ${ }^{1}$, MD. SHI MAJIB ${ }^{1}$ \\ ${ }^{1}$ National Center for Control of Rheumatic Fever and Heart Diseases (NCCRF\&HD), Sher-e-Bangla Nagar, Dhaka, \\ ${ }^{2}$ National Institute of Cardiovascular Disease (NICVD), Sher-e-Bangla Nagar, Dhaka
}

Address for correspondence: Dr. Md. Salehuddin, Asst. Prof. of Cardiology, National Center for Control of Rheumatic Fever and Heart Diseases, Sher-e-Bangla Nagar, Dhaka-1207, Bangladesh, E-mail:nccrfhd@hospi.dghs.gov.bd

\begin{abstract}
Non-communicable diseases (NCDs) such as cardiovascular diseases, diabetes mellitus, cancer, and chronic respiratory diseases are on the rise in South East Asia Region (SEAR). NCDs account for nearly 54\% of the deaths, significant amount of disabilities and huge socioeconomic losses in countries of SEAR. NCDs are caused by a set of behavioural risk factors, such as tobacco and alcohol consumption, physical activity and unhealthy diet (high in salt, sugar and fat and low in fruits and vegetables) and biological risk factors like raised blood pressure, raised blood sugar and impaired cholesterol levels and others.
\end{abstract}

South Asia is experiencing urbanization, with widening incme and social inequities. The impact of noncommunicable diseases on the rich and the poor are likely to be different, in terms of both the principal causes and manifestations. As the rich are likely to reconnise their risk earlier and seek medical attention, they will develop chronic but manageable disease; as the poor are likely to be less aware of their risk and less able to access medical care, they will develop rapidly progressive disease with early and sudden fatal outcomes To challenge to public health is to anticipate and avert an epidemic of non-communicable diseases.

NCDs risk factors can be reduced with existing knowledge through cost- effective policies and programmes, Establishment of surveillance systems for non-communicable diseases and their risk factors is essential for developing prevention strategies and monitoring the impact of control programmes.

Key Words: Non-communicable diseases, South Asia, Risk factors, Burden,

\section{Introduction}

The World Health Organization (WHO) stated in 2002 that "in many regions, some of the most formidable enemies of health are joining forces with allies of poverty to impose a double burden of disease, disability and premature death in many millions of people". 1

This is what is happening in South Asia, which has one quarter of the global population but where about half the population lives below the poverty line and has limited access to health care. Although infectious diseases remain a formidable enemy, the population is ageing and noncommunicable diseases are rising. ${ }^{2-4}$ South Asia has made fair economic progress in recent decades but is struggle to find a road towards sustainable development.

We review here the estimated burden of noncommunicable diseases in South Asia, the risk factors for these diseases, the limitations of the available data, and the attempts being made to gather evidence of better quality. We aim to provide a profile of non-communicable disease burden in this region.

\section{Sources and selection criteria}

We conducted a systemic search on Medline; used reports from WHO and other international organizations; and communicated with experts in the field. Although noncommunicable diseases have been variously defined, we propose to limit the term to three common risk factors: High blood pressure (Hypertension), High blood sugar (Diabetes mellitus) and abnormal pattern of blood fat level (Dyslipidemia). Tobacco use, dietary consumption patterns and physical inactivity are among the common risk behaviour shared by these disorders, providing common pathways of epidemiological transition as well as public health action.

Estimating the burden of non-communicable diseases Validated nationally representative estimates of cause specific mortality are not available for any country in South Asia. The available data are based on combinations of different datasets. In India, for example, deaths are registered as a part of "medical certification of cause of death" (registration of hospital deaths) and "survey of cause of death" ( a rural based registry). Other countries 
in the region provide mostly hospital based mortality data for assignment of cause of death. Population based estimates of mortality from non-communicable diseases are therefore difficult to produce: the urban data are based on inadequate death certification, and the rural data are limited by the inaccuracies in record keeping and partial coverage of health information systems.

\section{High blood pressure (Hypertension):}

Blood pressure denotes the force that the circulating blood exerts on the walls of the main arteries. The highest (systolic) pressure is created by the contraction of the heart, and the lowest (diastolic) pressure occurs while the left side of the heart is filling. It denotes the accommodation capacity of the circulating system. Raised blood pressure is sometimes without symptoms, which damage the arteries that supply blood to heart, brain, kidneys, eyes and elsewhere, producing a variety of structural changes. ${ }^{5}$ High blood pressure increases the heart's workload, causing the heart to thicken and become stiffer. It also increases the risk of stroke, heart attack, kidney failure and congestive heart failure. High blood pressure also leads to head and kidney failures, peripheral vascular disease and blindness. ${ }^{6}$ When high blood pressure exists with obesity, smoking, high blood cholesterol levels or diabetes, the risk of heart attack or stroke increases several times.

High blood pressure is a known disorder and a risk factor in SEAR. Results of a few population based surveys from the regional InfoBase are given in Table-I below. The proportion varies between 7-16\% ((more in urban areas) and proportion of known hypertensive on current treatment ranges from as low as $9 \%$ to $68 \%$. The overall prevalence of hypertension has rosen from a low of 4.3 in 1963 to as high as more than 50\% among specific communities in India and the current prevalence of hypertension is estimated to range between $20-40 \%$ in urban adults and $12-17 \%$ among rural adults. ${ }^{7}$ There are significant variations in hypertension across and with in countries. The treatment gap for hypertension is high due to inadequate recognition as well as treatment. Since the risk impact of hypertension can be reduced with available methods and there is need for targeting this at both population and individual levels. Similar to cholesterol, the relationship of blood pressure to CHD is linear, positive and graded with no discrenible lower threshold. According to the seventh report of the Joint national committee on Prevention, Detection, Evaluation and Treatment of high Blood Pressure, each difference of $20 \mathrm{mmHg}$ in systolic blood pressure is associated with 2-fold increase in relative risk of CHD, while a $5 \mathrm{~mm} \mathrm{Hg}$ reduction of SBP in the population would result in a $14 \%$ overall reduction in mortality due to stroke, a $9 \%$ reduction in mortality due to CHD and a 7\% decrease in all- cause mortality. The Asia Pacific Cohort Studies Collaboration indicates that a $2 \%$ reduction of population-wide mean diastolic blood pressure and a 7\% decline in those with DBP> $95 \mathrm{mmHg}$ has the potential to avert a total of 2 million deaths due to stroke and CHD by 2020 (approximately 15\% of all stroke deaths and $5 \%$ of all CHD deaths) in Asia. ${ }^{8}$ Such a strategy in India alone bringing a $2 \%$ reduction in mean population diastolic blood pressure can avoid 3,00,000 deaths due to stroke and CHD by 2020 AD.

Table-I

Prevalence of known hypertension and its treatment

\begin{tabular}{lccccccc}
\hline Country & \multicolumn{3}{c}{$\begin{array}{c}\text { Proportion with known } \\
\text { hypertension in last } 12 \text { months }\end{array}$} & & \multicolumn{3}{c}{$\begin{array}{c}\text { \% of known hypertensives } \\
\text { currently on medication }\end{array}$} \\
\cline { 2 - 4 } \cline { 7 - 8 } & Men & Women & Both sexes & & Men & Women & Both sexes \\
\hline India-R & 5.7 & 8.8 & 7.2 & & $\mathrm{NR}$ & $\mathrm{NR}$ & $\mathrm{NR}$ \\
India-U & 13.2 & 18.7 & 15.8 & & 68.7 & 67.6 & 68.1 \\
Indonesia* & $\mathrm{NS}$ & $\mathrm{NS}$ & $\mathrm{NS}$ & & $\mathrm{NS}$ & $\mathrm{NS}$ & $\mathrm{NS}$ \\
Maldives & 8 & 9 & 8,5 & & $\mathrm{NR}$ & $\mathrm{NR}$ & $\mathrm{NR}$ \\
Myanmar - R & 10.8 & 17.3 & 14.2 & & 9 & 10.1 & 9.7 \\
Myanmar - U & 14.1 & 22.2 & 18.3 & & 17.3 & 20.7 & 19.4 \\
Nepal & 6.9 & 7.2 & 7 & & 45.2 & 46.7 & 46 \\
Sri Lanka & $\mathrm{NR}$ & $\mathrm{NR}$ & $\mathrm{NR}$ & & $\mathrm{NR}$ & $\mathrm{NR}$ & $\mathrm{NR}$ \\
Thailand* & $\mathrm{NR}$ & $\mathrm{NR}$ & $\mathrm{NR}$ & & $\mathrm{NR}$ & $\mathrm{NR}$ & $\mathrm{NR}$ \\
All (range) & $6-14$ & $7-22$ & $7-16$ & & $9-69$ & $10-68$ & $10-68$ \\
\hline
\end{tabular}

- only national surveys, other are sub-national surveys; NR - not reported; NS - not studied 


\section{High Blood Sugar (Diabetes mellitus):}

Diabetes is a chronic condition that occurs when the pancreas does not produce enough insulin or when the body cannot effectively use the insulin it produces. Resulting high blood sugar levels and other related disturbances in the body's metabolism can lead to serious damage to many of the body's systems, especially the nerves and blood vessels. There are two basic forms of diabetes. In Type 1 diabetes, insulin production is very little or no insulin and such individuals will require daily injections of insulin to survive. In Type 2 diabetes mellitus (DM) individuals cannot use insulin effectively. Most people have type 2 diabetes and many of them have no symptoms and are only diagnosed after many years of onset. As a consequence, many people with type 2 diabetes are not aware that they have this life-threatening condition.

Diabetes mellitus is a strong risk factor for vascular diseases. Along with rising obesity and decreasing levels of physical activity, diabetes is also on the rise. While genetic susceptibilities of various racial and ethnic groups play a role, much of the increase in DM can be traced to changes in diet and physical activity. Migration studies suggest that South Asians and Indians also tend to be at higher risk than Europeans. ${ }^{9}$

Diabetes increases the risk of developing cardiovascular disease, stroke and cancers of breast, colon and uterus. Even when blood sugar levels are lower than the cut offs for the definition of overt diabetes, there is a graded increase in risk with increasing levels of blood sugar. The risk of heart attacks is enhanced greatly in the presence of other risk factors like high blood pressure or high serum cholesterol. ${ }^{10}$ About three-quarters of people with diabetes die of some form of heart or blood vessel disease. Each reduction of $1 \%$ in the Haemoglobin A1c, which measures the long term control of blood sugar levels, was associated with $14 \%$ reduction in myocardial infarction. ${ }^{11}$

The prevalence of diabetes and its adverse health effects has risen more rapidly in South Asia than in any other large region of the world. according to Global burden of diabetes study. ${ }^{12}$ India will have the largest diabetic population in the world with 57.2 million by 2025 which implies that the South Asian region will harbour the bulk of the global diabetes burden. Data from some population studies covered in the regional infoBase revel that the percent of population with known diabetes in SEAR varies between 1-7\%. A higher prevalence ranging between 2$15 \%$ have been reported by independent researchers. ${ }^{13}$ Men and women as affected equally increasing with age and with a greater predominance in urban areas. The proportion of people on medication ranges between 6$92 \%$, indicating huge treatment gap in some SEAR countries. Diabetes is likely to increase in the coming years and future projections are shown in Table-II and available data from SEAR InfoBase is shown in Table-III.

Table-II

Prevalence of \% diabetes in South Asia, 2000 and 2025 (projected in 1998) Values are percentages (number of people with diabetes)

\begin{tabular}{lcc}
\hline Country & 2000 & 2025 \\
\hline Bangladesh & $2.2(1564000)$ & $3.1(4032000)$ \\
Bhutan & $2.1(19000)$ & $2.3(39000)$ \\
India & $4.0(22878000)$ & $6.0(57243000)$ \\
Maldives & $2.5(3200)$ & $3.0(9200)$ \\
Nepal & $2.2(263000)$ & $2.6(638000)$ \\
Sri Lanka & $2.6(318000)$ & $3.5(617000)$ \\
\hline
\end{tabular}

Source: King H et al. Diabetes Care, 1998

Table-III

Prevalence of known diabetes and its treatment

\begin{tabular}{|c|c|c|c|c|c|c|}
\hline \multirow[t]{2}{*}{$\overline{\text { Country }}$} & \multicolumn{3}{|c|}{$\begin{array}{l}\text { Proportion with known } \\
\text { diabetes in last } 12 \text { months }\end{array}$} & \multicolumn{3}{|c|}{$\begin{array}{c}\text { \% on medication for raised blood } \\
\text { sugar in last } 12 \text { months }\end{array}$} \\
\hline & Men & Women & Both sexes & Men & Women & Both sexes \\
\hline India-R & 3.5 & 2.6 & 3.1 & 66.6 & 69.3 & 67.7 \\
\hline India-U & 7.1 & 6.7 & 6.9 & 73.1 & 80.1 & 74.7 \\
\hline Indonesia * & 1.2 & 1.1 & 1.2 & 79.5 & 67.5 & 72.5 \\
\hline Maldives & NR & NR & NR & NR & NR & NR \\
\hline Myanmar - R & 4.8 & 3.4 & 4.1 & 6.4 & 9 & 7.5 \\
\hline Myanmar - U & 3.8 & 4.5 & 4.2 & 22.2 & 25.2 & 23.8 \\
\hline Nepal & 1.8 & 1.8 & 1.8 & NR & NR & NR \\
\hline Sri Lanka & NR & NR & NR & NR & NR & NR \\
\hline Thailand * & NR & NR & NR & 36.2 & 52.2 & 45.3 \\
\hline All (range) & $1-7$ & $1-7$ & $1-7$ & $6-92$ & $9-80$ & $24-75$ \\
\hline
\end{tabular}

* - only national surveys, other are sub-national surveys; NR - not reported 


\section{Abnormal pattern of blood fat level (Dyslipidemia):}

Cholesterol is a fat-like substance, and in excess particularly the bad cholesterol or LDL cholesterol increases the risks of heart disease, stroke and other vascular diseases. Low levels of high-density lipoprotein (HDL) which is also commonly known as good cholesterol and elevated levels of low-density lipoprotein cholesterol(LDL-c) and triglycerides are also clearly associated with excess risk of CVDs. cholesterol in small amounts is required for the development of atherosclerosis (accumulation of fatty deposits on the inner lining of arteries). Unhealthy diet rich in animal fat and oils, heredity and some metabolic conditions such as diabetes determine an individual's level of LDL-cholesterol. ${ }^{13}$ The current levels of blood cholesterol level distribution in SEAR as seen in table 4 indicate that the percent of people with raised cholesterol levels varies from 13-55\% in member countries, Data reveal that high rates of raised blood cholesterol levels are seen in all countries, more so in India, Maldives and Thailand. The problem is more in urban areas and among women. As cholesterol levels increase with age, it has a cumulative and synergistic effect and results in NCDs. The high burden, availability of effective treatment and possibility of prevention offers a good scenario for prevention efforts.

Table-IV

Blood cholesterol level distribution

\begin{tabular}{lccccccc}
\hline Country & \multicolumn{2}{c}{ \% with raised total cholesterol $(>5.2 \mathrm{mmol} / \mathrm{l}$} & & \multicolumn{3}{c}{ Mean total cholesterol (mmol/l) } \\
\cline { 2 - 4 } & Men & Women & Both sexes & & Men & Women & Both sexes \\
\hline India - R & 18.5 & 25.6 & 22.1 & & 4.2 & 4.4 & 43 \\
India -U & 33.3 & 33.2 & 33.2 & & 4.7 & 4.8 & 4.7 \\
Indonesia* & 9 & 16 & 13.1 & & 4.4 & 4.6 & 4.5 \\
Maldives, & 53.6 & 55 & 54.4 & & 5.4 & 5.4 & 5.4 \\
Myanmar - R & 12.2 & 24.7 & 18.7 & & 4.1 & 4.5 & 4.3 \\
Myanmar- U & 21.9 & 29.2 & 25.8 & & 4.5 & 4.7 & 4.6 \\
Thailand* & 46.6 & 49.5 & 48.1 & & 5.2 & 5.3 & 5.2 \\
All (range) & $9-54$ & $16-55$ & $13-54$ & & $4.1-5.4$ & $4.5-5.4$ & $4.3-5.4$ \\
\hline
\end{tabular}

- only national surveys, other are sub-national surveys

\section{Risk factors co-exist}

Table-V

Summary results of NCD risk factor surveys using STEPS approach in the SEA Region; both sexes; 2003-5

\begin{tabular}{|c|c|c|c|c|c|c|c|c|}
\hline Country/site & $\begin{array}{c}\text { Current } \\
\text { smokers } \\
(\%)\end{array}$ & $\begin{array}{c}\text { Current } \\
\text { consumer of } \\
\text { alcohol (\%) }\end{array}$ & $\begin{array}{c}\text { \% eating } \\
<5 \text { servings } \\
\text { of } \mathrm{F} \& \mathrm{~V}\end{array}$ & $\begin{array}{l}\% \text { physically } \\
\text { inactive }\end{array}$ & $\begin{array}{c}\% \\
\text { overweight } \\
\text { and obese }\end{array}$ & $\begin{array}{c}\% \text { with } \\
\text { raised blood } \\
\text { pressure }\end{array}$ & $\begin{array}{l}\text { \% with } \\
\text { raised fasting } \\
\text { blood sugar }\end{array}$ & $\begin{array}{c}\% \text { with } \\
\text { raised blood } \\
\text { cholesterol }\end{array}$ \\
\hline Bangladesh - R & 25.3 & NS & NR & NR & 8.6 & NR & NS & NS \\
\hline Bangladesh - U & 21.9 & NS & NR & NR & 36.5 & NR & NS & NS \\
\hline India -R & 17.8 & 26.4 & 84.6 & 10 & 13.3 & 20.3 & 6.6 & 22.1 \\
\hline India -U & 15.7 & 20.7 & 81.4 & 23.8 & 39.4 & 24.3 & 10.9 & 33.2 \\
\hline Indonesia - & 32 & 3.3 & 94.5 & 7.8 & 22.3 & 35.9 & 5.2 & 13.1 \\
\hline Maldives- Male & 22.7 & NS & 84.6 & NR & 44.2 & NR & NR & 54.4 \\
\hline Myanmar- R & 24.4 & 18 & 98.2 & 3.5 & 23.3 & 11.9 & 3.8 & 18.7 \\
\hline Myanmar- U & 22.9 & 18.4 & 99.1 & 7.3 & 36.5 & 25 & 7.7 & 25,8 \\
\hline Nepal & 20.6 & 40.5 & 99.1 & NR & 16.5 & 42 & NS & NS \\
\hline Sri Lanka & 19.6 & 40.5 & 96.8 & 14.9 & 28.8 & 7.8 & NS & NS \\
\hline Thailand & 18.6 & 40.1 & 85 & NR & 37.5 & 22.4 & 8.6 & 48.1 \\
\hline Total (range) & $16-32$ & $3-41$ & $81-99$ & $4-24$ & $9-44$ & $8-42$ & $4-9$ & $13-54$ \\
\hline
\end{tabular}

only national surveys, other are sub-national surveys; F\&V- fruit and vegetable; NS - not studied; NR - not reported; R - rural; U - urban 
Table-VI

Attributable years of life lost (YLL) by risk factor, sex and mortality stratum in SOUTH - EAST ASIA, estimates for 2000

\begin{tabular}{llccccc}
\hline Risk factors & & \multicolumn{3}{c}{ Mortality stratum } \\
\cline { 3 - 4 } & & & \multicolumn{2}{c}{ LMDR (000) } & & \multicolumn{2}{c}{ HMDR (000) } \\
\cline { 3 - 3 } \cline { 5 - 6 } & & Male & Female & & Male & Female \\
\hline 1. & High blood pressure & 1225 & 1231 & & 6176 & 4619 \\
2. & High blood Cholesterol & 731 & 356 & & 4927 & 4722 \\
3. & Overweight & 448 & 565 & & 486 & 1273 \\
4. & Low fruits and Vegetable intake & 549 & 455 & & 3699 & 3054 \\
5. & Physical Inactivity & 342 & 330 & & 2135 & 1811 \\
6. & Tobacco use & 2066 & 135 & & 8660 & 1403 \\
7. & Alcohol use & 1156 & 189 & & 2936 & 462 \\
8. & Urban Air pollution & 154 & 128 & & 718 & 594 \\
9. & Indoor smoke from solid fuels & 386 & 390 & & 6324 & 7140 \\
\hline
\end{tabular}

HMDR- High mortality developing region (Bangladesh, Bhutan, India, Maldives, Myanmar, Nepal, Timor-Leste),LMDRlow mortality developing region (Indonesia, SriLanka, Thailand)Attributable years of life lost (YLL)- sum of the years of life lost due to premature mortality (YLL) as a result of exposure to a particular risk factor. World health report 2002

All these risk factors are potentially modifiable and are good starting points for prevention. The findings of INTERHEART are similar to the estimates of the Global burden study in which $45.7 \%$ of global mortality and $20.7 \%$ of global burden of disease were attributed to 7 risk factors like high blood pressure, high cholesterol, high body mass index, low fruits and vegetable intake, physical inactivity, tobacco use and alcohol use. In addition, the study showed that South Asians developed first heart attack six years earlier than populations of other countries. ${ }^{14}$ The earlier age of heart attack in South Asians could largely be explained by higher risk factor levels at younger ages. it was found that the risk factors such as physical inactivity, lack of fruits and vegetables consumption, elevated lipids were higher even among south Asian control than from other countries. The world health report of 2002 revealed that attributable years of life lost due to these risk factors was significantly high and more so in rapidly progressing nations of SEAR (Table-VI).

\section{Conclusions}

The health burdens of non-communicable diseases are high in South Asia, though there are differences among countries and with in urban and rural areas of each country, depending on the level of developmental and epidemiological transition. Many of these disease burdens occur in the productive mid-life period and will, therefore, adversely affect workforce productivity and economic development. Although the absence of well established disease surveillance mechanisms prevents precise estimation of the size of non-communicable disease burdens, their risk factors, and time trends would help to better inform policy and to monitor change in response to public health interventions. Even at the current state of knowledge, however, the magnitude of the problem is large enough to demand urgent attention and action.

\section{References:}

1 The World Health Report 2002 - Reducing risks, promoting healthy life. Geneva, World Health Organization, 2002.

2 Murray CJL, Lopez AD, eds. The global burden of disease: a comprehensive assessment of mortality and disability from diseases, injuries and risk factors in 1990 and projected to 2020. Cambridge, MA, Harvard School of Public Health on behalf of the World Health Organization and the World Bank, 1996.

3 Murray CJL, Lopez AD, eds. Global burden of diseases. Harvard School of Public Health, 1996. (Vol 1 of Global Burden of Disease and Injury series).

4 Ezzati M, Hoorn SV, Rodgers A, Lopez AD, Mathers CD, Murray CJ; Comparative Risk Assessment Collaborating Group. Estimates of global and regional potential health gains from reducing multiple major risk factors. Lancet, 2003, 362: 27180 .

5 Nishtar S. Prevention of coronary heart disease in south Asia. Lancet 2002; 360: 1015-8. [Cross Ref] [ISI] [Medline]

6 The World Health Report 1997- Tobacco or Health: A Global Status Report. Geneva, World Health Organization, 1997.

7 King H, Aubert RE, Herman WH. Global burden of siabetes, 1995-2025: prevalence, numerical estimates and projections. Diabetic Care 1998; 21: 14-31

8 International Diabetes Federation. Diabetes atlas 2000. Brussls: IDF, 2000 
9 Ramachandran A, Snehalatha C, Kapur, et al. High prevalence of diabetes and impaired glucose intolerance in India: national urban survey. Diabetologia 2001;44:1094-101.

10 Ramachandra A, Snehatha C et al. Metabolic syndrom in urban Asian Indian adults-a population study using modified ATP III criteria. Diabetes Clin Pract 2003;60:199-204.

11 World Health Organization Expert Consultation. Appropriate body-mass index for Asian population and its implications for policy ans intervention strategies. Lancet 2004;363:157-63.

12 Kannel WB, McGee DL. Diabetes and cardiovascular disease: the Framingham Study. Journal of the American Medical Association, 1979,241:2035-38.

13 WHO Technical Report Series 2002, No. 916- Diet, Nutrition And The Prevention Of Chronic Diseases. Geneva: World Health Organization; 2002.

14 Yusuf S, Hawken S, Ounpuu S, Dans T, Avezum A, Lanas F, et al; INTERHEART Study Investigators. Effect of potentially modifiable risk factors associated with myocardial infarction in 52 countries (the INTERHEART study): case-control study. Lancet, 2004, 364: 937-52.
15 Diet, Nutrition and the Prevention of Chronic Diseases. Report of a joint WHO/FAO expert consultation. Geneva, World Health Organization, 2003.

16 World Health Organization / International Society of Hypertension statement on management of hypertension. Journal of Hypertension 2003; 21: 1983-92.

17 Gupta R. Trends in hypertension epidemiology in India. Journal of Human Hypertension, 2004,18: 73-78.

18 The Seventh Report of Joint National Committee on prevention, detection, evaluation, and treatment of high blood pressure: the JNC 7 report. Journal of the American Medical Association, 2003,289:2560-72.

19 World Health Organization. WHO Global InfoBase online (http:// www.who.int/ncd_ surveillance/infobase/web/ InfoBaseCommon/).

20 World Health Organization. Information sheet: Chronic disease - key risk factors include high cholesterol, high blood pressure, low fruit and vegetable intake. WHO 2003 (Available: http://www.who.int/dietphysicalactivity/publications/facts/ riskfactors/en/, accessed 21 November 2006) 